\title{
A team approach to improving colorectal cancer services using administrative health data
}

\author{
Geoffrey Porter ${ }^{1,2,3,4^{*}}$, Robin Urquhart ${ }^{4}$, Jingyu Bu ${ }^{4,5}$, Cynthia Kendell ${ }^{4}$, Maureen Maclntyre ${ }^{5}$, Ron Dewar ${ }^{5}$, \\ George Kephart ${ }^{3}$, Yukiko Asada ${ }^{3}$ and Eva Grunfeld ${ }^{6,7}$
}

\begin{abstract}
Background: Colorectal cancer (CRC) is the third most commonly diagnosed cancer in Canada and accounts for $11.9 \%$ of all cancer-related mortality. Fortunately, previous studies have provided evidence of improved outcomes from access to timely and appropriate health services along the disease trajectory in CRC. As a result, the CIHR/ CCNS Team in Access to Colorectal Cancer Services in Nova Scotia (Team ACCESS) was created to build colorectal cancer (CRC) research capacity in Nova Scotia (NS) and to study access to and quality of CRC services along the entire continuum of cancer care.
\end{abstract}

Objectives: The objectives of this paper are to: 1) provide a detailed description of the methodologies employed across the various studies being conducted by Team ACCESS; 2) demonstrate how administrative health data can be used to evaluate access and quality in CRC services; and 3) provide an example of an interdisciplinary team approach to addressing health service delivery issues.

Methods: All patients diagnosed with CRC in NS between 2001 and 2005 were identified through the Nova Scotia Cancer Registry (NSCR) and staged using the Collaborative Stage Data Collection System. Using administrative databases that were linked at the patient level, Team ACCESS created a retrospective longitudinal cohort with comprehensive demographic, clinical, and healthcare utilization data. These data were used to examine access to and quality of CRC services in NS, as well as factors affecting access to and quality of care, at various transition points along the continuum of care. Team ACCESS has also implemented integrated knowledge translation strategies targeting policy- and decision- makers.

Discussion: The development of Team ACCESS represents a unique approach to CRC research. We anticipate that the skills, tools, and knowledge generated from our work will also advance the study of other cancer disease sites in NS. Given the increasing prevalence of cancer, and with national and provincial funding agencies promoting collaborative research through increased funding for research team development, the work carried out by Team ACCESS is important in the Canadian context and exemplifies how a team approach is essential to comprehensively addressing issues surrounding not only cancer, but other chronic diseases in Canada.

Keywords: Colorectal cancer, interdisciplinary research, health services, administrative health data

\section{Background}

\subsection{Colorectal Cancer}

In Canada, an estimated 22,200 new cases of colorectal cancer (CRC) were diagnosed in 2011, making it the third most commonly diagnosed cancer in both men and women in Canada [1]. Despite a modest decrease in national mortality rates over the last 20 years, CRC

\footnotetext{
* Correspondence: Geoff.Porter@cdha.nshealth.ca

'Queen Elizabeth II Health Sciences Centre, Halifax, Nova Scotia, Canada Full list of author information is available at the end of the article
}

mortality still accounts for approximately $11.9 \%$ of cancer-related deaths [1].

Nova Scotia (NS) has the second highest incidence rate of CRC of all Canadian provinces, with an estimated 830 new cases in 2011 [1]. Interestingly, estimated mortality rates are higher ( 30 vs. 25 per 100, 000 people) [1] and estimated 5-year relative survival rates are lower in NS (56\% vs. 62\%) [2] compared to Canada, suggesting poorer patient outcomes for CRC patients in NS than other provinces. Previous studies have provided

C Biomed Central

(c) 2012 Porter et al; licensee BioMed Central Ltd. This is an Open Access article distributed under the terms of the Creative Commons Attribution License (http://creativecommons.org/licenses/by/2.0), which permits unrestricted use, distribution, and reproduction in any medium, provided the original work is properly cited. 
evidence of improved outcomes from access to timely and appropriate health services along the disease trajectory in CRC and other malignancies [3,4], highlighting the need for improved research into CRC services in NS.

\subsection{Team ACCESS}

Team ACCESS was formed in 2007 after receiving a New Emerging Team (NET) grant from the Canadian Institutes of Health Research (CIHR). These grants are awarded to encourage the formation of new research teams and to build capacity in new and developing areas of research. Team ACCESS is an interdisciplinary team consisting of more than 20 researchers and decisionmakers (i.e., clinicians, program managers/directors, policy-makers) from a broad range of methodological and health disciplines. Collectively, Team ACCESS possesses expertise in health services research, epidemiology, biostatistics, population health, health administration, primary care, psychiatry, pediatrics, pathology, and surgical, medical, and radiation oncology. Through this unprecedented collaborative research effort in NS, Team ACCESS has sought to improve the capacity to examine access to and quality of CRC services at transition points across the entire continuum of cancer care (i.e., presentation of signs/symptoms, diagnosis, surgery, systemic and radiation therapy, follow-up care, and advanced disease/palliative care). Such transitions may be particularly susceptible to problems of access and quality since they often require patients to move across health care sectors as part of a complex and fragmented delivery system [5].

The specific research objectives of Team ACCESS are to; 1 ) develop tools to measure and improve timely and equitable access to, and quality of, CRC services along the cancer care continuum, 2) explore methods to integrate access and quality relevant to CRC services, and measure the impact on outcomes, and, 3) develop and test methods for the knowledge transfer of findings towards improving access to quality CRC care.

Importantly, at the time this award was received, Team ACCESS was the only team in Canada that was examining CRC health services across the entire continuum of care. After four years of research in this area, we know of no other group in Canada that is examining CRC in such a comprehensive manner.

\section{Objectives}

The aim of this paper is to provide an account of the expertise and preliminary work required to study CRC services along the cancer care continuum. Specifically, the objectives of this paper are to: 1) provide a detailed description of the methodologies employed across the various studies being conducted by Team ACCESS; 2) demonstrate how administrative health data can be used to evaluate access and quality in CRC services; and 3) provide an example of an interdisciplinary team approach to addressing health service delivery issues.

\section{Methods}

Team ACCESS has embarked on more than 20 studies to date (Table 1), with most now completed or nearing completion. These studies span the entire continuum of care, from presentation of signs/symptoms, to diagnosis, treatment, follow-up care, and advanced disease/palliative care. While the methods used may vary from study to study (depending on the research question), the methods presented in this section are common to all studies.

\subsection{Cohort Identification}

To maximize generalizability, a population-based cohort was identified. All incident cases of CRC (ICD-O-3: C18, C19, C20) in NS between 2001 and 2005 were identified through the Nova Scotia Cancer Registry (NSCR). To define the study cohort, we excluded; 1 ) cases diagnosed by death certificate only or autopsy, 2) individuals less than 20 years of age, and 3) diagnoses of appendix cancer (ICD-O-3: C18.1), lymphoma, noninvasive CRC, and invasive Stage 0 CRC [6]. For patients with more than one CRC diagnosis in the time period, we kept only one record per patient (Figure 1). Of the selected 3,501 patients that comprise the final study cohort, 2,385 (68.1\%) had colon cancer and 1,116 (31.9\%) had rectal cancer. Their demographic and disease characteristics are described in Table 2.

\subsection{Cohort Staging}

Since treatment for CRC depends on stage at diagnosis [7], stage data are key in examining issues surrounding timely receipt of quality care and the impact on patient outcomes. In Canada, staging data have not historically been collected by provincial cancer registries [8], as was the case in NS. Upon cohort identification, Team ACCESS collaborated with experienced coders at the NSCR to conduct an extensive chart review and stage all CRC cases using the Collaborative Stage (CS) Data Collection System, resulting in CS derived AJCC stage groups [6,9]. CS uses information from multiple sources to determine a "best" stage, effectively reducing the number of unknown stages within a population [10], contributing to the completeness of our data.

\subsection{Data Sources}

At the center of Team ACCESS research is a longitudinal 'database' assembled by linking individual patient records across the administrative health databases used in the study. Complete data (i.e. data from all databases) are available from January 1, 1999 to March 31, 2008. 
Table 1 Summary of Team ACCESS research

\begin{tabular}{|c|c|c|}
\hline Area of Study & Research Question/Study & Theme(s) \\
\hline \multirow{3}{*}{$\begin{array}{l}\text { From screening/symptoms to } \\
\text { diagnosis }\end{array}$} & What are the peri-diagnostic time intervals for CRC care? What factors affect receipt of timely care? & Access \\
\hline & $\begin{array}{l}\text { What factors related to pre-CRC diagnosis health care utilization are associated with late stage diagnosis } \\
\text { of CRC? }\end{array}$ & $\begin{array}{l}\text { Access, } \\
\text { Quality }\end{array}$ \\
\hline & $\begin{array}{l}\text { Using micro-simulation, how will introduction of a population-based screening program impact on } \\
\text { resource and health services utilization? }\end{array}$ & Access \\
\hline \multirow[t]{6}{*}{ From diagnosis to surgery } & What are the surgical time intervals for CRC care? What factors affect receipt of timely care? & Access \\
\hline & Are there differences in the use of health care services for emergency vs. elective presentation of CRC? & $\begin{array}{l}\text { Access, } \\
\text { Quality }\end{array}$ \\
\hline & Has adequate lymph node assessment improved over time? & Quality \\
\hline & What are the effects of lymph node assessment on overall CRC survival? & Quality \\
\hline & Exploring Stage IIB survival: can we identify factors associated with poor outcomes in Stage IIB patients? & $\begin{array}{l}\text { Access, } \\
\text { Quality }\end{array}$ \\
\hline & Timely access to and quality of care in CRC: are they related? & $\begin{array}{l}\text { Access, } \\
\text { Quality }\end{array}$ \\
\hline \multirow{5}{*}{$\begin{array}{l}\text { From surgery to adjuvant } \\
\text { treatment } \\
\text { (chemotherapy/ } \\
\text { radiotherapy) }\end{array}$} & What are the treatment time intervals for adjuvant CRC care? What factors affect receipt of timely care? & Access \\
\hline & Is adjuvant therapy administered in accordance with established clinical practice guidelines? & $\begin{array}{l}\text { Access, } \\
\text { Quality }\end{array}$ \\
\hline & What are the reasons for non-adherence to guidelines? & Quality \\
\hline & Does inequity exist in meeting established benchmarks for radiotherapy and in receipt of treatment? & $\begin{array}{l}\text { Access, } \\
\text { Quality }\end{array}$ \\
\hline & $\begin{array}{c}\text { What is the completeness of colonoscopy, surgery, and pathology reporting for rectal cancer patient } \\
\text { receiving radiotherapy? }\end{array}$ & Quality \\
\hline \multirow[t]{4}{*}{$\begin{array}{l}\text { From adjuvant treatment to } \\
\text { follow-up care }\end{array}$} & What are the patterns of follow-up care for CRC? & $\begin{array}{l}\text { Access, } \\
\text { Quality }\end{array}$ \\
\hline & Is follow-up care being provided according to established clinical practice guidelines? & $\begin{array}{l}\text { Access, } \\
\text { Quality }\end{array}$ \\
\hline & How do patients feel about the follow-up care they receive? & $\begin{array}{l}\text { Access, } \\
\text { Quality }\end{array}$ \\
\hline & Are $C R C$ survivors receiving appropriate screening services for other cancers? & Access \\
\hline \multirow[t]{2}{*}{ End-of-life care } & What are the patterns of medication use amongst end-of-life CRC patients? & $\begin{array}{l}\text { Access, } \\
\text { Quality }\end{array}$ \\
\hline & Does inequity exist in health care utilization for CRC patients at end-of life? & Access \\
\hline Knowledge Translation & Which approaches/strategies are useful in integrating research findings into clinical practice? & \\
\hline
\end{tabular}

The earlier years of data permit the study of healthcare utilization for the two years preceding diagnosis for all patients in the cohort. Table 3 presents the databases used by Team ACCESS, as well as the main variables extracted from each database.

As previously discussed, the cohort was identified through the NSCR. In NS, all new cancer diagnoses are reportable to the NSCR by law. The NSCR is operated by the Surveillance and Epidemiology Unit (SEU) at Cancer Care Nova Scotia (CCNS) and has data dating back to 1964. In NS, the SEU houses both the NSCR and the Oncology Patient Information System (OPIS), the administrative scheduling system for the province's two tertiary care cancer centres, resulting in a single database that contains both cancer registry and cancer centre data. Thus, for each patient included in the cohort, the following information was extracted from NSCR/OPIS: patient demographics, previous and subsequent primary cancers, diagnosis and staging, cancer center referrals, treatment-related and cancer recurrence visits, and radiotherapy treatments.

Through the Population Health Research Unit (PHRU) at Dalhousie University, we accessed and linked information from a variety of administrative health care databases [11]. The NS Department of Health (DoH) supplies PHRU with complete Medicare and hospital files suitable for research purposes. In accordance with DoH policy, all data held at PHRU uses an encrypted health card number to maintain patient confidentiality.

Other databases, held at individual departments/programs, were used by Team ACCESS to obtain additional information relevant to CRC services and/or patients. 


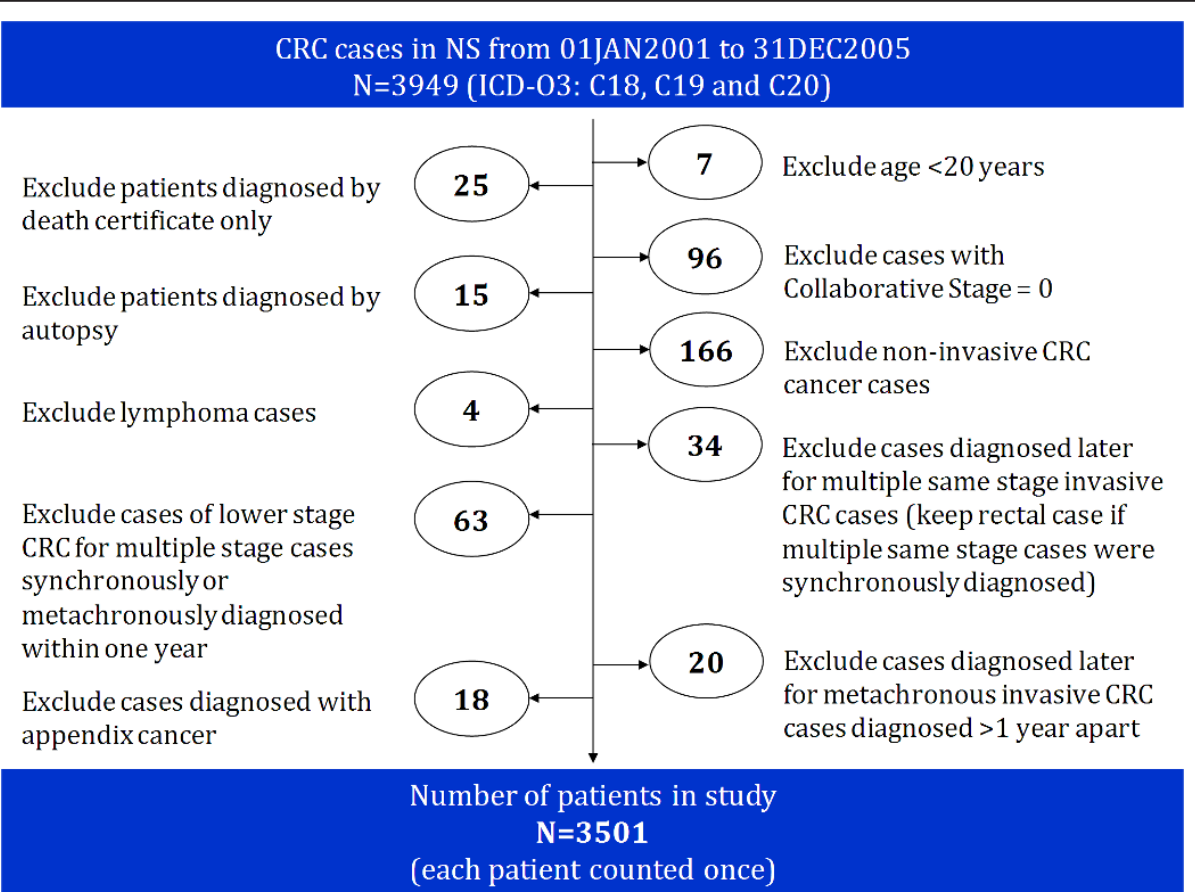

Figure 1 Cohort identification.

Table 2 Characteristics of study cohort

\begin{tabular}{lr}
\hline Cohort Characteristics & $\mathbf{n}(\%)$ \\
\hline Sex & \\
$\quad$ Memale & $1634(46.7)$ \\
$\quad$ Agale & $1867(53.3)$ \\
\hline 20-64 Diagnosis & \\
65-74 & $1122(32.0)$ \\
75+ & $941(26.9)$ \\
\hline Rural/urban residence & $1438(41.1)$ \\
Rural & \\
Urban & $1424(40.7)$ \\
\hline Comorbidity score & $2077(59.3)$ \\
0 & \\
1+ & $2031(58.0)$ \\
\hline Collaborative stage & $1470(42.0)$ \\
I & \\
II & $659(18.8)$ \\
IIA & $1069(30.5)$ \\
IIB & $882(25.2)$ \\
III & $187(5.3)$ \\
IIIA & $916(26.2)$ \\
IIIB & $88(2.5)$ \\
IIIC & $555(15.9)$ \\
IV & $273(7.8)$ \\
Unknown & $697(19.9)$ \\
\hline
\end{tabular}

The databases accessed include; Capital District Health Authority's Radiology Department (CHRD) database, Capital District Health Authority's and Cape Breton District Health Authority's Palliative Care Program (PCP) databases, the CCNS Cervical Cancer Prevention Program (CCPP) database, and the Nova Scotia Breast Screening Program (NSBSP) database.

\subsection{Data Linkage}

To facilitate data linkage, a unique study ID was appended to each of the identified NSCR records. As shown in Figure 2, data linkage consisted of two processes:

1) To link NSCR data to PHRU data, the health card number $(\mathrm{HCN})$ and unique study ID from the identified records were sent to the provincial healthcare administrator for $\mathrm{HCN}$ encryption. The unique study ID and encrypted HCN were then sent to PHRU. The information contained within the NSCR records (i.e., staging, demographics, cancer clinic visit activity, etc.) was sent directly to PHRU with only the unique study ID as a person-level identifier. Using the unique study ID, the encrypted HCN was re-assigned to the corresponding patient record to enable linkage to PHRU data.

2) To link NSCR data to the remaining databases, patient identifiers (i.e., $\mathrm{HCN}$, date of birth, surname) 
Table 3 List of administrative health databases accessed and the main variables extracted

\begin{tabular}{|c|c|}
\hline Database & Variables \\
\hline $\begin{array}{l}\text { Nova Scotia Cancer Registry (NSCR)/Oncology Patient } \\
\text { Information System }\end{array}$ & $\begin{array}{l}\text { - Patient demographics } \\
\text { - Diagnosis and staging } \\
\text { - Cancer center referrals and visits } \\
\text { - Treatment information } \\
\text { - Previous and subsequent primary cancers } \\
\text { - Cancer recurrence }\end{array}$ \\
\hline Mental Health Outpatient Information System (MHOIS) & $\begin{array}{l}\text { - Mental health clinic visits } \\
\text { - Demographics } \\
\text { - Diagnoses }\end{array}$ \\
\hline Medical Service Insurance Physician Services (MSIPS) & $\begin{array}{l}\text { - Physician visits } \\
\text { - Diagnoses } \\
\text { - Procedures }\end{array}$ \\
\hline Medical Service Insurance (MSI) Insured Patient Registry & $\begin{array}{l}\text { - Patient demographics } \\
\text { - Enrollment status } \\
\text { - Program eligibility dates }\end{array}$ \\
\hline Licensed Provider Registry & $\begin{array}{l}\text { - Physician demographics } \\
\text { - Physician specialty } \\
\text { - Educational information }\end{array}$ \\
\hline Vital Statistics & $\begin{array}{l}\text { - Patient demographics } \\
\text { - Dates of death } \\
\text { - Cause of death }\end{array}$ \\
\hline Discharge Abstract Database (DAD) & $\begin{array}{l}\text { - Hospital discharges } \\
\text { - Diagnoses } \\
\text { - Procedures }\end{array}$ \\
\hline Canadian 2001 Census Data & $\begin{array}{l}\text { Neighborhood or community level measures: } \\
\text { - Education } \\
\text { - Income } \\
\text { - Rural/urban residency }\end{array}$ \\
\hline Seniors' PharmaCare Prescriptions (SP) & $\begin{array}{l}\text { Prescription data for individuals } 65 \text { years and older: } \\
\text { - Drug ID } \\
\text { - Cost } \\
\text { - Amount }\end{array}$ \\
\hline Community Services Prescriptions (CSP) & $\begin{array}{l}\text { Prescription data for individuals less than } 65 \text { years who are enrolled in a provincial } \\
\text { income assistance program: } \\
\text { - Drug ID } \\
\text { - Cost } \\
\text { - Amount }\end{array}$ \\
\hline Nova Scotia Breast Screening Program & $\begin{array}{l}\text { - Procedure dates } \\
\text { - Procedure types } \\
\text { - Screening results } \\
\text { - Diagnoses }\end{array}$ \\
\hline Cervical Cancer Prevention Program & $\begin{array}{l}\text { - Smear dates } \\
\text { - Diagnosis dates } \\
\text { - Healthcare professional specialty }\end{array}$ \\
\hline $\begin{array}{l}\text { Capital Health Radiology Department } \\
\text { (CHRD) }\end{array}$ & $\begin{array}{l}\text { - Radiology procedure codes } \\
\text { - Procedure dates }\end{array}$ \\
\hline $\begin{array}{l}\text { Palliative Care Programs }(P C P)^{*} \\
\text {. }\end{array}$ & - Referral/enrollment date into a formal PCP \\
\hline
\end{tabular}

* Only available for the two districts with formal PCPs (i.e., Capital District Health Authority and Cape Breton District Health Authority)

and unique study ID for all CRC patients were sent to the dataset custodians at CHRD, PCP, CCPP, and NSBSP. All records that corresponded to patients in our cohort were identified within each database using the $\mathrm{HCN}$ and confirmed using the patient identifiers. The data custodian then extracted these records, removed all identifying information from the file, except the unique study ID, and sent the file to PHRU for linkage to NSCR records via unique study ID.

\subsection{Measures}

\subsubsection{Overarching Themes}

The themes of access and/or quality are explored in each Team ACCESS study (see Table 1), with the overall objectives of integrating access and quality relevant to CRC services, and developing tools to assess these dimensions of the healthcare system.

Access to care is measured in terms of equity [12] and timeliness [13]. Specifically, Team ACCESS uses a 


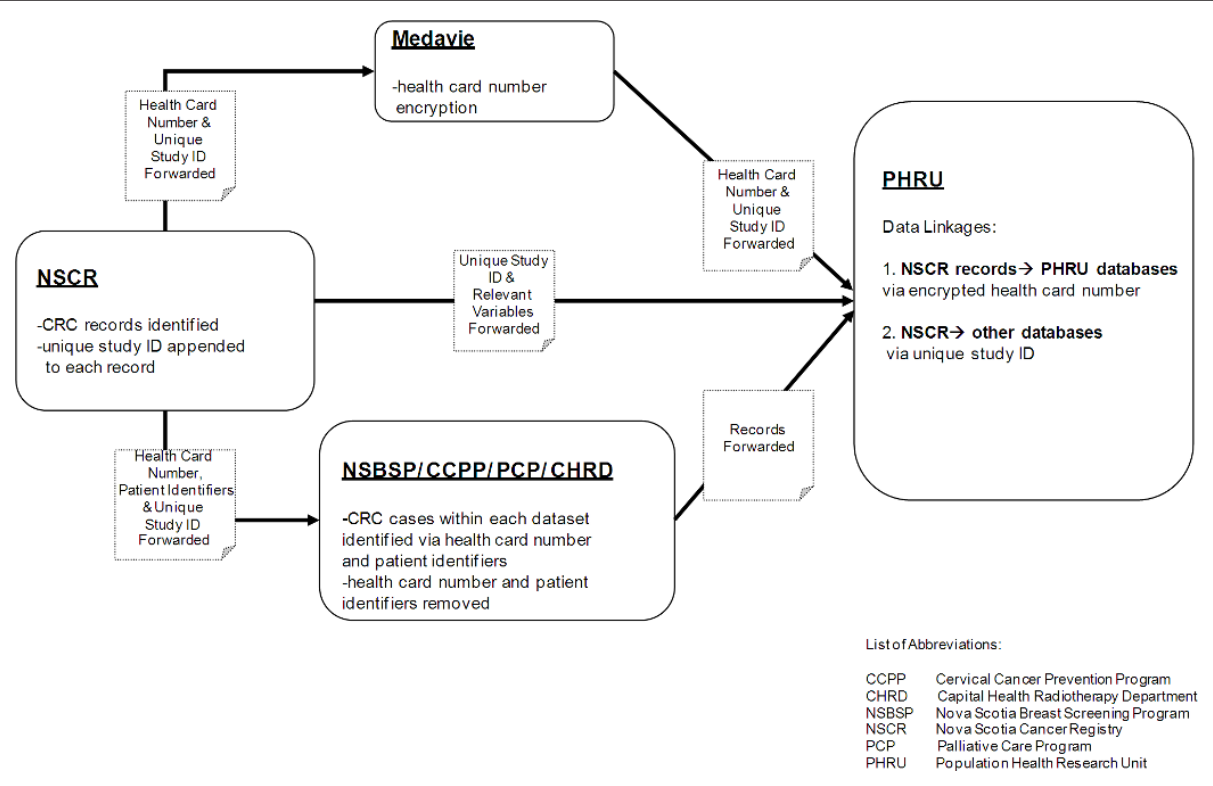

Figure 2 Data linkage.

needs-based approach [14] to determine whether those who should be receiving care, according to clinical practice guidelines (CPGs) and patients' needs profiles, are receiving it in a timely manner (according to CPGs and established benchmarks). At each stage along the cancer care continuum, the effect of various factors (i.e., age, sex, clinical, geographical and socioeconomic factors, and special needs of vulnerable populations [15]) on access to CRC services is investigated. Quality is assessed using documented cancer care quality indicators (QIs) [16] and/or adherence to CPGs. Where CPG adherence is low, reasons for non-adherence are being explored. Such reasons have been studied using the linked administrative data or, in certain situations, have required a focused chart review. To maintain patient confidentiality, chart reviews are undertaken in partnership with the NSCR, which holds the key for the unique study ID, with data subsequently linked in the manner described above.

\subsubsection{Covariates}

All of our studies examine the influence of geography (e. g., urban/rural residence, health district, and distance to specialized services) as well as other patient characteristics (e.g., age, sex, cormorbidity, and neighborhood socioeconomic status) on the access and quality measure studied. To maintain methodological consistency across studies, team members collaborated to define the following covariates:

1) Comorbidity is assessed using a comorbidity score and a cancer history variable. A modified list of comorbidities was created using those identified by Elixhauser et al [17], with coding (ICD-9-CM and ICD-10) developed by Quan et al [18]. Cancer-related comorbidities were excluded, resulting in a list of 28 comorbidities. Using this list, an unweighted comorbidity count was obtained for each individual by examining hospital discharge records for two years prior to the index CRC diagnosis to 30 days after diagnosis (potential score: 028). Using NSCR data, a cancer history variable was created by counting each individual's previously diagnosed primary cancers. The comorbidity score and the cancer history variable are used as separate covariates for statistical analyses.

2) In addition to examining several variables independently (e.g., median household income, education), we use a deprivation index to measure socioeconomic status. This index includes both material deprivation and social deprivation as previously described by Townsend [19]. Using the "Quebec Model" [20], six indicators of material and social deprivation (proportion of persons with a high school diploma, employment/population ratio, average income, proportion of persons living alone, proportion of single parent families, and proportion of separated, divorced, and widowed persons) were extracted from census data. These indicators were used to generate material and social deprivation values for patients' census dissemination areas (DAs). Index values range between 0 and 4 , with 4 being the least deprived. Patient postal codes at the time of diagnoses are linked, via the Postal Code Conversion File Plus $\left(\mathrm{PCCF}^{+}\right)$[21], to a specific DA (as defined by 2001 census data) and assigned the associated deprivation index values for that area.

3) Rurality is defined using the Statistical Area Classification (SACtype) and the Metropolitan and Census 
Agglomeration Influenced Zones (MIZ) classification developed by Statistics Canada to distinguish rural and urban areas [22,23]. Patients' postal codes obtained at the time of diagnoses were inputted into the $\mathrm{PCCF}^{+}[21]$ to obtain a SAC type/MIZ value. If a patient resides in a census metropolitan area (CMA) or census agglomeration (CA), or in a zone that is strongly influenced by a CMA or CA, his/her location of residence is considered urban. A rural residence is defined as being located in a zone that is not strongly influenced by a CMA or CA.

\section{Results/Discussion}

The development of Team ACCESS represents a unique approach to cancer research, and specifically to CRC research. Prior to Team ACCESS, a formal research collaboration of this magnitude had not existed in NS, limiting the quality and breadth of CRC research conducted in the province. In addition, collaborations and partnerships have been established with local, provincial, and national cancer groups/organizations that further improve our research capacity by providing opportunities for dialogue on CRC and ongoing feedback, and thus contributing to our understanding of the issues that affect the cancer care system and the patients who use it.

Overall, Team ACCESS has made substantial contributions to CRC research. The first notable contribution being the development of research capacity in NS by assembling an interdisciplinary team, mentoring clinicians (with limited research experience), and training graduate students (MSc, $\mathrm{PhD}$, and post-doctoral fellows) in cancer health services research. Second, by staging all CRC cases diagnosed in NS between 2001 and 2005, population-level stage data are available for a 5-year time period. Since treatment for CRC depends upon the stage at diagnosis [7], such data are vital to examining quality of care issues in CRC. Third, the creation of the Team ACCESS database linkage permits a thorough assessment of health system utilization in relation to CRC across the entire continuum of cancer care.

In addition to conducting research, Team ACCESS is focused on effecting change in the health care system through knowledge translation (KT) activities and collaborations with leaders in cancer research and cancer services. Specifically, we have taken an integrated KT approach by involving decision-makers in the development, conduct, and interpretation phases of research. We anticipate this approach will advance CRC care in the province in two ways: 1 ) by helping decision-makers facilitate changes in CRC programs and services based on the research findings; and 2) by helping researchers align their research questions and studies with issues relevant to the local decision-making communities.
These contributions illustrate how a team approach is essential to improving colorectal cancer services in NS. Our assessment of inequity in the colorectal cancer care system further exemplifies the importance of a team approach. Adopting a needs-based approach to inequity analysis, and moving beyond studying variations in care to understanding whether the variations are based on patients' needs or some non-need factors (e.g., sex, socio-economic status), has required expertise from a diverse team - specifically, researchers and analysts to facilitate database linkage, experts in inequity analysis and the specific analytic techniques (e.g., horizontal inequity index), oncologists with specific clinical knowledge (e.g., related to curative and palliative therapies) to help define need versus non-need variables and then appropriately interpret the findings, and individuals with knowledge translation experience to help translate the findings and their implications to the clinical and decision-making communities.

Our study of inequity moved beyond studying variations in care, to examining whether these variations in care are based on patients' needs or some non-need factors (e.g., sex, socio-economic status). This needs-based approach to inequity analysis has required expertise from a diverse team- researchers and analysts to facilitate database linkage, experts in inequity analysis and the specific analytic techniques (e.g., horizontal inequity index), oncologists with specific clinical knowledge (e.g., related to curative and palliative therapies) to help define need versus non-need variables and then appropriately interpret the findings, and individuals with knowledge translation experience to help translate the findings and their implications to the clinical and decision-making communities.

Our research has identified several limitations in data availability and capture in our province. Specifically, direct access to laboratory data was not available and chemotherapy data were incomplete. Regarding the latter, chemotherapy can be administered on an outpatient basis, often by nurses $[8,24]$, without an associated physician billing. We have performed a chart review to obtain complete chemotherapy data. Moreover, several of the databases are not population-based (i.e., CHRD, PCP, and PharmaCare), but rather are limited to certain jurisdictions or patient populations (e.g., those 65 years of age and older), limiting our capacity to report upon diagnostic imaging, palliative care, and medication use for the entire province.

Team ACCESS developed out of a recognized need to study and improve access to quality CRC services in NS. The significance of this team is underscored by the involvement of many key decision/policy-makers, clinical leaders, and senior researchers from other disciplines (e.g., epidemiology, database analysis, equity analysis) to 
work on this topic. We anticipate that the skills, tools, and knowledge generated from our work will also advance the study of other cancer disease sites in NS. Our approach may also be adapted to study other chronic conditions and understand issues regarding access to and quality of care, and their impact on outcomes, in these patient populations.

\section{Acknowledgements and Funding}

Team ACCESS consists of a number of clinicians and researchers, each of whom has contributed clinical and methodological expertise to the body of work outlined in this manuscript (a complete list of team members can be found at http://www.teamaccess.ca). We would like to gratefully acknowledge the Nova Scotia Cancer Registry staff for their work on identifying and staging the cohort. We also acknowledge Charmaine Cooke and Dr. Jennifer Payne for their guidance on particular databases, Margaret Jorgenson for administrative support, and Martha Cox for analytic support. Grant support for Team ACCESS is provided by the Canadian Institutes of Health Research (CIHR), Cancer Care Nova Scotia, the Government of Nova Scotia Department of Health, Capital District Health Authority, Dalhousie Medical Research Foundation, and Dalhousie University Faculty of Medicine.

\section{Author details}

'Queen Elizabeth II Health Sciences Centre, Halifax, Nova Scotia, Canada. 2Department of Surgery, Dalhousie University, Halifax, Nova Scotia, Canada. ${ }^{3}$ Department of Community Health and Epidemiology, Dalhousie University, Halifax, Nova Scotia, Canada. ${ }^{4}$ Cancer Outcomes Research Program, Cancer Care Nova Scotia, Halifax, Nova Scotia, Canada. ${ }^{5}$ Surveillance and Epidemiology Unit, Cancer Care Nova Scotia, Halifax, Nova Scotia, Canada. ${ }^{6}$ Ontario Institute for Cancer Research, Toronto, Ontario, Canada. 7 Department of Family and Community Medicine, University of Toronto, Toronto, Ontario, Canada.

\section{Authors' contributions}

GP and RU were involved in the conception of Team ACCESS, conception and design of specific research studies, and analysis and interpretation of data. JB was involved in the design of several individual studies, analysis and interpretation of data, and manuscript preparation. CK was involved the coordination of studies, interpretation of data, and drafting of the manuscript. MM was involved in cohort identification, database linkage, and analysis and interpretation of data. RD was involved in cohort identification, database linkage, the development of common methodologic structures and tools and analysis and interpretation of data. GK was involved in the conception of Team access, development of common metholodgic structures and tools. YA was involved in development of common metholodgic structures and tools. EG was involved in the conception of Team ACCESS and conception and design of specific research studies. All authors revised the manuscript critically for important intellectual content and approved the final manuscript.

\section{Competing interests}

The authors declare that they have no competing interests.

Received: 26 August 2011 Accepted: 31 January 2012 Published: 31 January 2012

\section{References}

1. Canadian Cancer Society: Canadian Cancer Statistics 2011 Toronto, ON; 2011.

2. Canadian Cancer Society: Canadian Cancer Statistics 2009 Toronto, ON; 2009.

3. Hershman DL, Wang X, McBride R, Jacobson JS, Grann VR, Neugut A: Delay in initiating adjuvant radiotherapy following breast conservation surgery and its impact on survival. Int I Radiat Oncol Biol Phys 2006, 65(5):1353-1360

4. Berrino F, De Angelis R, Sant M, Rosso S, Lasota MB, Coebergh JB, et al: Survival for eight major cancers and all cancers combined for European adults diagnosed in 1995-99: results of the EUROCARE-4 study. Lancet Oncol 2007, 8(9):773-783.
5. In Strengthening the quality of cancer services in Ontario. Edited by: Sullivan T, Evans W, Angus H, Hudson A. Ottawa: CHA Press; 2003:

6. Collaborative Staging Task Force of the American Joint Committee on Cancer: Collaborative Staging Manual and Coding Instructions, version 01.04.00. Jointly published by American Joint Committee on Cancer (Chicago, IL) and U.S. Department of Health and Human Services (Bethesda, MD); 2007 [http://www.cancerstaging.org/cstage/manuals.html].

7. $\mathrm{NIH}$ Consensus Conference: Adjuvant therapy for patients with colon and rectal cancer. JAMA 1990, 264(11):1444-1450.

8. Urquhart R, Grunfeld E, Porter GA: Synoptic reporting and the quality of cancer care: a review of evidence and Canadian initiatives. OE 2009, 8(1):28-31.

9. American Joint Committee on Cancer: AJCC Cancer Staging Handbook from the AJCC Cancer Staging Manual, $6^{\text {th }}$ ed. New York, NY: Springer; 2002.

10. Phillips JL, Gress DM: Comparison of registrar collaborative staging and physician AJCC staging using data submitted to the National Cancer Data Base. J Registry Management 2008, 35(1):4-11.

11. Population Health Research Unit. [http://www.phru.dal.ca].

12. Asada Y: A framework for measuring health inequity. J Epidemiol Community Health 2005, 59:700-705.

13. Wait Time Alliance for Timely Access to Health Care: It's about time: Achieving benchmarks and best practices in wait time management. Ottawa, ON: Canadian Medical Association; 2005 [http://www.cma.ca/ multimedia/CMA/Content_Images/Inside_cma/Media_Release/pdf/2005/ wta-final.pdf].

14. O'Donnell O, van Doorslaer E, Wagstaff A, Lindelow M: Analyzing health equity using household survey data: A guide to techniques and their implementation Washington, DC: The World Bank; 2008.

15. Hoffmaster B: What does vulnerability mean? Hastings Cent Rep 2006, 36(2):38-45

16. Urquhart R, Grunfeld E: Measuring the quality of care provided to patients with colorectal cancer: the potential of quality indicators. $O E$ 2009, 8(4):6-10.

17. Elixhauser A, Steiner C, Harris DR, Coffey RM: Comorbidity measures for use with administrative data. Med Care 1998, 36(1):8-27.

18. Quan H, Sundararajan V, Halfon P, Fong A, Burnand B, Luthi JC, et al: Coding algorithms for defining comorbidities in ICD-9-CM and ICD-10 administrative data. Med Care 2005, 43(11):1130-1139.

19. Townsend P: Deprivation. J Soc Policy 1987, 16(2):125-146.

20. Pampalon $R$, Raymond $\mathrm{G}$ : A deprivation index for health and welfare planning in Quebec. Chronic Dis Can 2000, 21(3):104-113.

21. Census of Canada: Postal Code Conversion File, PCCF+ Version 4J, September 2006 Postal Codes, 2001[2007]. Ottawa, ON.

22. Statistics Canada: 2001 Census Dictionary.[http://www12.statcan.ca/english/ census01/Products/Reference/dict/].

23. McNiven C, Puderer H, Janes D: Census Metropolitan Area and Census Agglomeration Influenced Zones (MIZ): A Description of the Methodology. Geography Division, Statistics Canada; 2000.

24. Rayson D, Urquhart R, Colwell B, Grunfeld E: Limitations of chemotherapy data in administrative health databases: implications for measuring and improving quality of colorectal cancer care [abstract]. Can J Gastroent 2010, 24:A193.

doi:10.1186/1478-4505-10-4

Cite this article as: Porter et al:: A team approach to improving colorectal cancer services using administrative health data. Health Research Policy and Systems 2012 10:4. 